\title{
Proton-detected scalar coupling based assignment strategies in MAS solid-state NMR spectroscopy applied to perdeuterated proteins
}

\author{
Rasmus Linser ${ }^{\mathrm{a}}$, Uwe Fink ${ }^{\mathrm{a}}$, Bernd Reif ${ }^{\mathrm{a}, \mathrm{b}, *}$ \\ a Leibniz-Institut für Molekulare Pharmakologie (FMP), Campus Berlin-Buch, Robert-Rössle Strasse 10, 13125 Berlin, Germany \\ ${ }^{\mathrm{b}}$ Charité Universitätsmedizin, D-10115 Berlin, Germany
}

\section{A R T I C L E I N F O}

\section{Article history:}

Received 31 January 2008

Revised 4 April 2008

Available online 6 May 2008

\section{Keywords:}

Magic angle spinning (MAS)

Perdeuteration

Protein resonance assignment

Scalar coupling based magnetization

transfers

\begin{abstract}
A B S T R A C T
Assignment of proteins in MAS (magic angle spinning) solid-state NMR relies so far on correlations among heteronuclei. This strategy is based on well dispersed resonances in the ${ }^{15} \mathrm{~N}$ dimension. In many complex cases like membrane proteins or amyloid fibrils, an additional frequency dimension is desirable in order to spread the amide resonances. We show here that proton detected HNCO, HNCA, and HNCACB type experiments can successfully be implemented in the solid-state. Coherences are sufficiently long lived to allow pulse schemes of a duration greater than $70 \mathrm{~ms}$ before incrementation of the first indirect dimension. The achieved resolution is comparable to the resolution obtained in solution-state NMR experiments. We demonstrate the experiments using a triply labeled sample of the SH3 domain of chicken $\alpha$-spectrin, which was re-crystallized in $\mathrm{H}_{2} \mathrm{O} / \mathrm{D}_{2} \mathrm{O}$ using a ratio of $1 / 9$. We employ paramagnetic relaxation enhancement (PRE) using EDTA chelated $\mathrm{Cu}^{\mathrm{II}}$ to enable rapid data acquisition.
\end{abstract}

(C) 2008 Elsevier Inc. All rights reserved.

\section{Introduction}

Solid-state NMR is more and more becoming a standard technique for protein structure determination without the molecular weight limits that solution-state NMR suffers from. The combination of magic angle spinning (MAS) solid-state NMR [1] and Cross Polarisation (CP) [2] paved the way for investigations of larger spin systems. Methodological and conceptual improvements, however, are still necessary for a straight forward and routine application of solid-state NMR to biological matter. Nevertheless, its applicability to a wide range of candidates for biomolecular investigation like uniformly isotopically enriched membrane proteins [3-6] or proteins forming aggregates [7-12] has been demonstrated.

Usually, assignment of proteins in the solid-state is based on correlations among heteronuclei like ${ }^{13} \mathrm{C}$ or ${ }^{15} \mathrm{~N}$, employing NCACX or NCOCX type experiments [13-15]. This strategy relies on well dispersed resonances in the ${ }^{15} \mathrm{~N}$ dimension. Protons, which are excessively used in solution-state NMR because of their high gyromagnetic ratio, normally do not play a big role in solid-state NMR except for providing starting points for magnetization transfer prior to CP. In conventional solid-state NMR, ${ }^{1} \mathrm{H}$ detection is usu-

\footnotetext{
* Corresponding author. Address: Leibniz-Institut für Molekulare Pharmakologie (FMP), Abteilung Festkirper-NMR: Proteinaggregation und Membranproteine, Campus Berlin-Buch, Robert-Rössle Strase 10, 13125 Berlin, Germany. Fax: +49 30 94793199.

E-mail address: reif@fmp-berlin.de (B. Reif).
}

ally less favorable, as large dipolar couplings lead to substantial line broadening. We and others showed that this disadvantage can be circumvented by a reduction of the samples' proton density [16-23]. This allows to detect protons with high sensitivity and resolution. Effective proton dilution, i.e., re-crystallization of the perdeuterated protein in $\mathrm{H}_{2} \mathrm{O}: \mathrm{D}_{2} \mathrm{O}$ at a ratio of $1: 9$, combined with fast $(\approx 20 \mathrm{kHz})$ MAS has been shown to result in ${ }^{1} \mathrm{H}$ line widths in the order of $20 \mathrm{~Hz}$ [24]. Despite the high degree of deuteration, the $T_{1}$ relaxation times of the residual protons are still reasonably short. This resolution at hands, a large variety of experimental possibilities are emerging, including the localization of water molecules [25], determination of ${ }^{1} \mathrm{H},{ }^{1} \mathrm{H}$ long range distances $[16,26]$ and access to clean backbone relaxation parameters [27-31]. In addition, deuterons allow to probe dynamic properties of amino acid side chains [32,33].

In addition, this labeling scheme opens up new ways for resonance assignment. We demonstrate in this article that slightly modified solution-state pulse sequences like HNCO [34,35], HNCA [34,35], and HNCACB [36] can be successfully applied to micro-crystalline samples in the solid-state. Pulse sequences in which magnetization is mediated through bonds via scalar couplings become more and more important for solid-state NMR [37-39], as only chemically bonded atoms are correlated to each other resulting in clean correlation spectra. The inclusion of the ${ }^{1} \mathrm{H}$ chemical shift in the assignment process yields a better chemical shift dispersion of the amide moiety and decreases the number of ambiguously assigned residues. We ex- 
pect that, this way, the reliability of chemical shift assignment and, thus, the quality of structure determination in solid-state NMR can be significantly improved.

\section{Methods}

As a model system, we use a micro-crystalline samples of the SH3-domain of $\alpha$-spectrin. Triply labeled protein was recombinantly expressed, purified as described before [24]. Crystallization was performed by $\mathrm{pH}$-shift using a $5 \mathrm{mg} / \mathrm{ml}$ protein solution in a crystallization buffer containing $\mathrm{H}_{2} \mathrm{O}: \mathrm{D}_{2} \mathrm{O}$ at a ratio of $1: 9$. Paramagnetic relaxation enhancement (PRE) was used in order to decrease the recycle delay of the experiment [40,41]. For that purpose, $[\mathrm{Cu}(\text { edta })]^{2-}$ was added upon crystallization at a concentration of 75 and $150 \mathrm{mM}$ as described earlier [41]. Crystals were packed by centrifugation into 3.2 and $4 \mathrm{~mm}$ rotors, respectively.

NMR experiments were carried out under MAS (14 and $24 \mathrm{kHz}$, as indicated in the respective figures) using Bruker Avance spectrometers operating at ${ }^{1} \mathrm{H}$ Larmor frequencies of 400,600 , and $700 \mathrm{MHz}$. In all experiments, ${ }^{15} \mathrm{~N}$ chemical shift is evolved in a constant-time manner during the reverse INEPT step in which the ${ }^{15} \mathrm{~N},{ }^{13} \mathrm{C}$ scalar coupling is refocused. Pulse programs were adapted from Bruker standard programs employing the sequences suggested by Kay, Bax, Müller and co-workers for HNCO [34,35], HNCA [34,35], and HNCACB [36] (Fig. 1). Modifications of the pulse schemes involve simplified solvent suppression due to the little amount of residual water in the micro-crystals. Soft rectangular instead of shaped pulses were used in the case of on-resonance ${ }^{13} \mathrm{C}$ selective irradiation in order to cut down the length of the overall sequence. Scalar heteronuclear decoupling during acquisition was applied using a RF field strength in the order of $2 \mathrm{kHz}$. A RF field strength of $4.2 \mathrm{kHz}$ was employed for ${ }^{1} \mathrm{H}$ DIPSI-2 decoupling during periods of transverse ${ }^{15} \mathrm{~N}$ and ${ }^{13} \mathrm{C}$ magnetization. The recycle delays of the experiments were set to 1.3 times ${ }^{1} \mathrm{H} \mathrm{T} T_{1}$. The increments in the indirect dimensions were adjusted to yield spectral windows of 12,25 , and $70 \mathrm{ppm}$ for $\mathrm{CO}, \mathrm{C}^{\alpha}$, and $\mathrm{C}^{\alpha / \beta}$, respectively. Unless stated otherwise, the chemical shifts were evolved to a maximum acqui- sition time of $t_{1}^{\max }=15,9$, and $8 \mathrm{~ms}$ for $\mathrm{CO}, \mathrm{C}^{\alpha}$, and $\mathrm{C}^{\alpha / \beta}$, respectively. The ${ }^{15} \mathrm{~N}$ spectral width was set to $27 \mathrm{ppm}$. $\tau$ and $\Delta$ were adjusted to 2.3 and $3.6 \mathrm{~ms}$. $T$ was set to $12 \mathrm{~ms}$ (HNCA and HNCO) or $12.4 \mathrm{~ms}$ (HNCACB), respectively. The nominal sample temperature is indicated in the respective figures. The effective sample temperature is higher as MAS results in an additional temperature increase of around 12 and $25^{\circ} \mathrm{C}$ in the case of 14 and $24 \mathrm{kHz}$ spinning, respectively.

\section{Results and discussion}

Employing PRE, we could reduce the recycle delays in the experiments to 840 and $300 \mathrm{~ms}$ for samples containing $75 \mathrm{mM} \mathrm{Cu}^{\mathrm{II}}$ (sample A, packed into a $3.2 \mathrm{~mm}$ rotor) and $150 \mathrm{mM} \mathrm{Cu}^{\mathrm{II}}$ (sample B, packed into a $4 \mathrm{~mm}$ rotor), respectively. Nevertheless, the overall acquisition times amounted to approximately 2 days (HNCO, sample A) and 2 days (HNCA, for sample B), and 4.5 days (HNCACB, sample $B$ ) due to the reduced proton abundance, resulting in an approximate signal-to-noise ratio of $45: 1,25: 1$, and 16:1, respectively. Recently, Rienstra and co-workers introduced a proton detected $\mathrm{CON}(\mathrm{H}) \mathrm{H}$ experiment in the context of determination of ${ }^{1} \mathrm{H},{ }_{1} \mathrm{H}$ distances [23]. The $\mathrm{CON}(\mathrm{H}) \mathrm{H}$ yields similar connectivity information as the HNCO, but relies on dipolar interactions to transfer magnetization. Fig. 2 represents a projection of the 3D HNCO spectrum onto the ${ }^{1} \mathrm{H}^{\mathrm{N}}$, CO plane. The excellent resolution allows to easily identify the different residues without having to struggle with signal overlap even in the 2D experiment. Signalto-noise amounted to $15 \%$ compared to a standard HSQC. Given the fact that ${ }^{15} \mathrm{~N} \mathrm{~T}_{2}$ is in the order of $100 \mathrm{~ms}$ [28], one would expect the HNCO peak intensity to be in the order of around 35\% compared to the HSQC correlation experiment. We attribute the discrepancy between the observed and theoretically expected HNCO intensity to poor RF inhomogeneity of MAS solid-state probes and to partial recoupling of the ${ }^{1} \mathrm{H},{ }^{15} \mathrm{~N}$ dipolar interactions during the DIPSI-2 decoupling periods.

Fig. 3 represents ${ }^{1} \mathrm{H}^{\mathrm{N}},{ }^{13} \mathrm{C}^{\alpha}$ strips of sequentially neighboring residues in the $3 \mathrm{D}$-HNCA spectrum extracted at the indicated ${ }^{15} \mathrm{~N}$
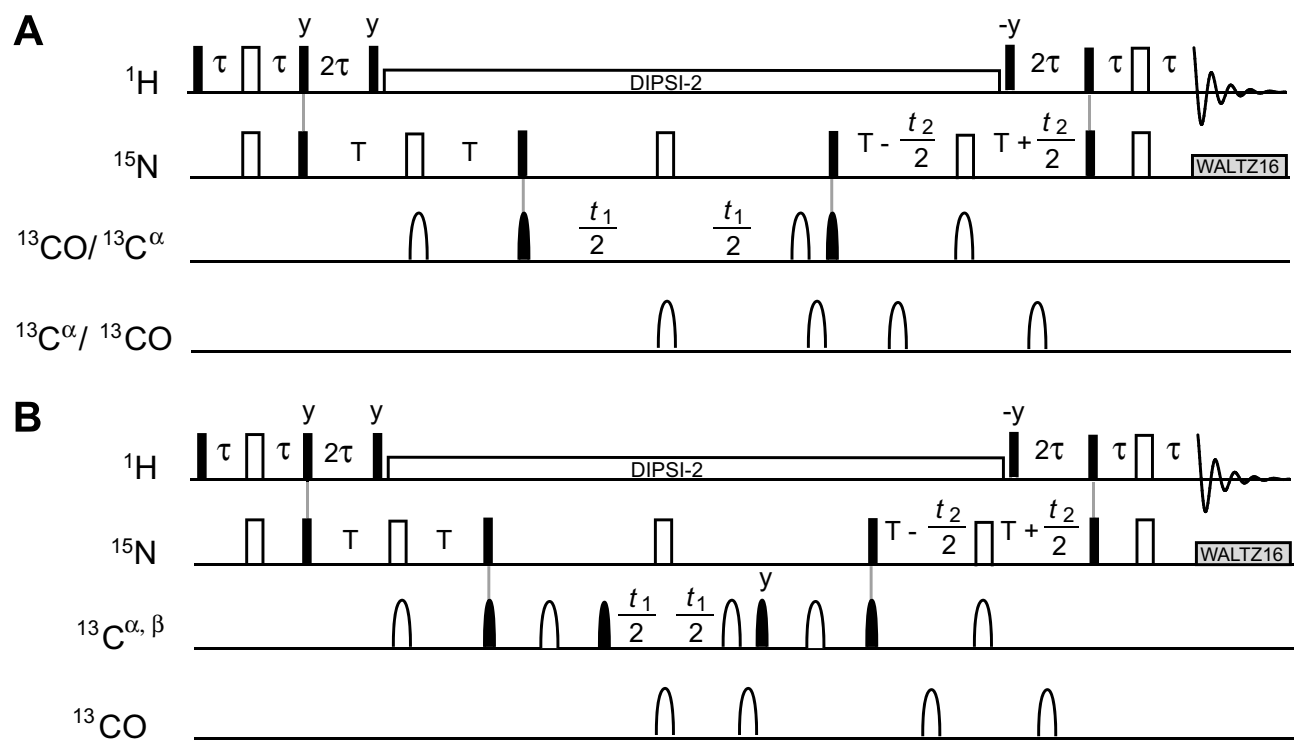

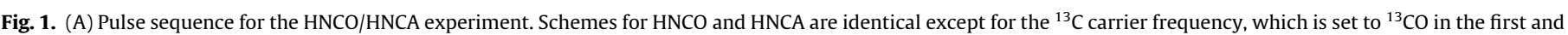

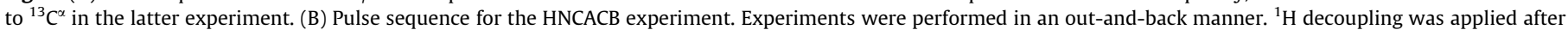

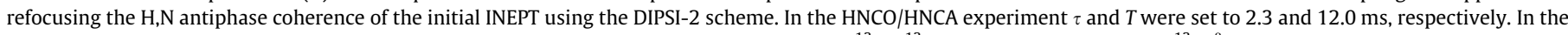

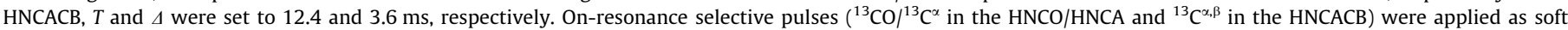

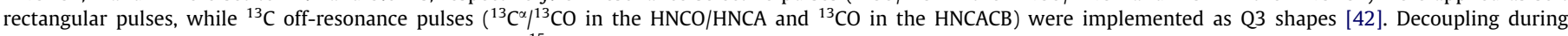
acquisition was achieved using WALTZ-16, adjusting the ${ }^{15} \mathrm{~N}$ RF field to $2 \mathrm{kHz}$. 


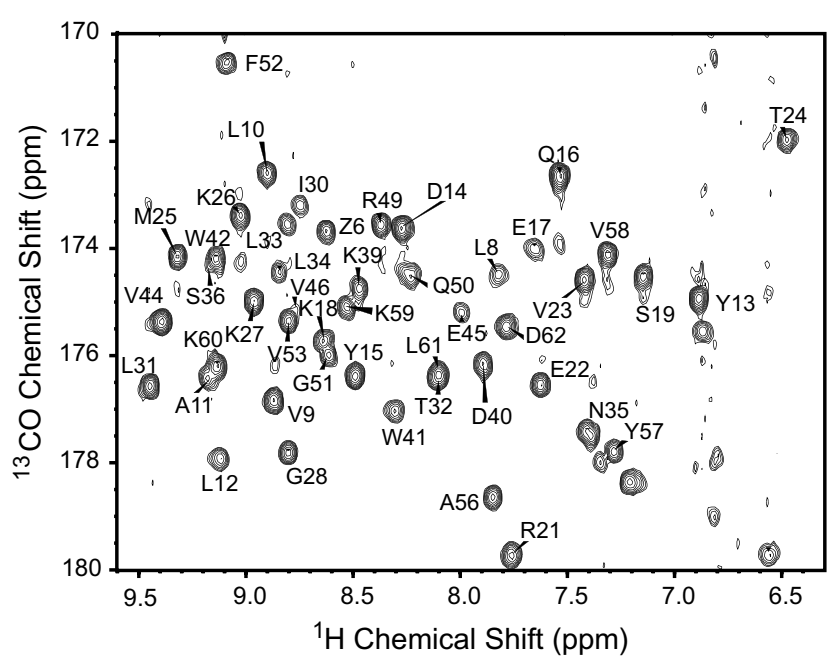

Fig. 2. 2D projection onto the ${ }^{1} \mathrm{H},{ }^{13} \mathrm{CO}$ plane of the $\mathrm{HNCO}$ experiment recorded at $400 \mathrm{MHz}{ }^{1} \mathrm{H}$ Lamor frequency and $24 \mathrm{kHz}$ spinning. High resolution is even obtained in the 2D projection due to the small proton line width. Exponential line broadening of $5 \mathrm{~Hz}$ was used for processing in the ${ }^{1} \mathrm{H}$ dimension. The indirect dimension covers a spectral width of $12 \mathrm{ppm}$ and was incremented to a maximum evolution time of $14.5 \mathrm{~ms}$.

chemical shifts. The HNCA experiment was recorded for sample B

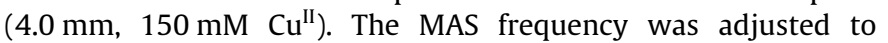
$14 \mathrm{kHz}$. In principle, similar results were obtained for sample A, which was packed into a $3.2 \mathrm{~mm}$ rotor. Compared to an HSQC, an average intensity of approximately $7 \%$ was obtained. Compared to an HNCO, the efficiency of the HNCA is reduced by a factor of two due to the distribution of magnetization among two coupling partners $\left(C_{i}^{\alpha}\right.$ and $\left.C_{i-1}^{\alpha}\right)$ and due to the smaller ${ }^{1} J$-coupling. In the HNCA, all residues show two peaks, originating from the amino acid $(i)$ and $(i-1)$. As the ${ }^{2} J_{\mathrm{NC}}$ coupling of approximately $7 \mathrm{~Hz}$ is slightly smaller than the ${ }^{1} J_{\mathrm{NC}}$ coupling $(\approx 11 \mathrm{~Hz})$, signals stemming from the inter-residual correlation tend to be slightly less intense, giving hints for the assignment process.

Residues that were not assigned in the dipolar coupling based original assignment $[43,44]$ could so far not be assigned either, despite the fact that the $2 \mathrm{D}{ }^{1} \mathrm{H},{ }^{15} \mathrm{~N}$ correlation using INEPT for magnetization transfer yields more correlations peaks. Already in the HSQC, the signal-to-noise of these residues is significantly reduced compared to other correlations, which probably results from their increased flexibility. Correlations involving these resonances could not be detected in the 3D experiments due to further magnetization decay in the course of the pulse sequence. We tried to circumvent this problem by variation of the sample temperature. Increase of the temperature should enhance local motions and, thus, yield line narrowing in cases where conformational exchange induces line broadening. Problematic residues in this respect are residues located at the N- and C-terminus, residues S36-N38 and the residues of the flexible loop region N47-D48. At low temperature $\left(T^{\text {nominal }}=285 \mathrm{~K}\right)$, e.g., the C-terminal D62 has a significantly lower intensity and is not observed in the HNCA, while we find an intensity comparable to the other residues at $300 \mathrm{~K}$. S36, on the other hand, is not detectable in the HNCA at neither temperature, indicating fast relaxation due to internal mobility. Similarly, K43 is not observable at $14 \mathrm{kHz}$ spinning and $T^{\text {nominal }}=285$ and $300 \mathrm{~K}$. All residues (S36, K43, and D62), however, are observed in the experiment performed at $24 \mathrm{kHz}$ spinning $\left(T^{\text {nominal }}=275 \mathrm{~K}\right)$, which yields an overall higher signal-to-noise ratio.

In the HNCACB, the (see Fig. 4) signal intensity is distributed among four resonances in the ${ }^{13} \mathrm{C}$ dimension. In addition, the

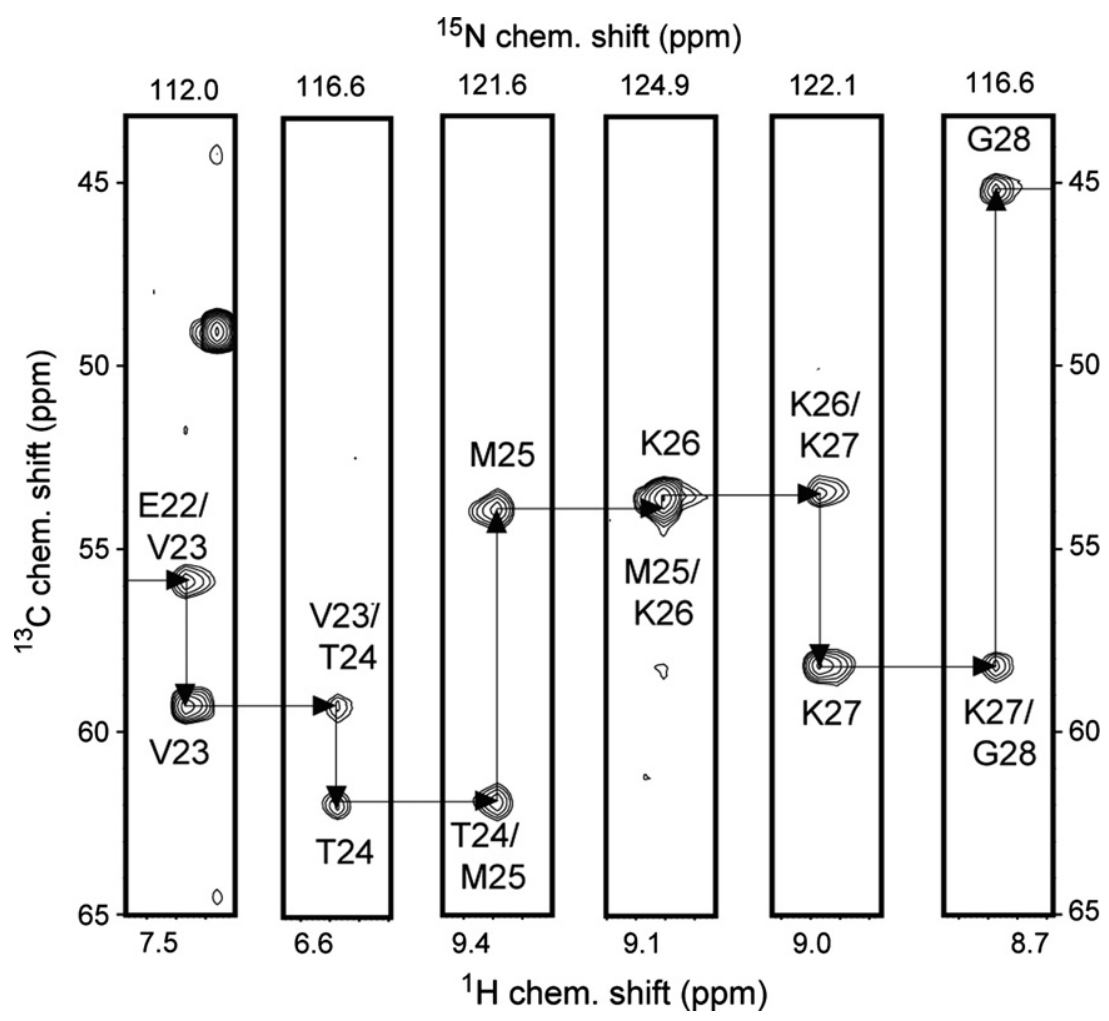

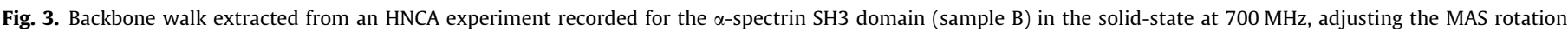

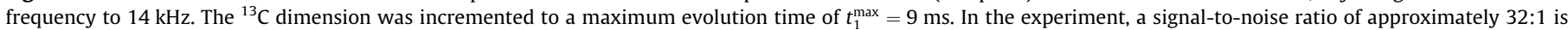

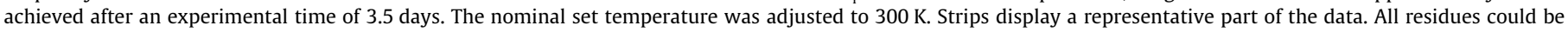
assigned except those in the flexible loop and at the N-terminus of the protein. 


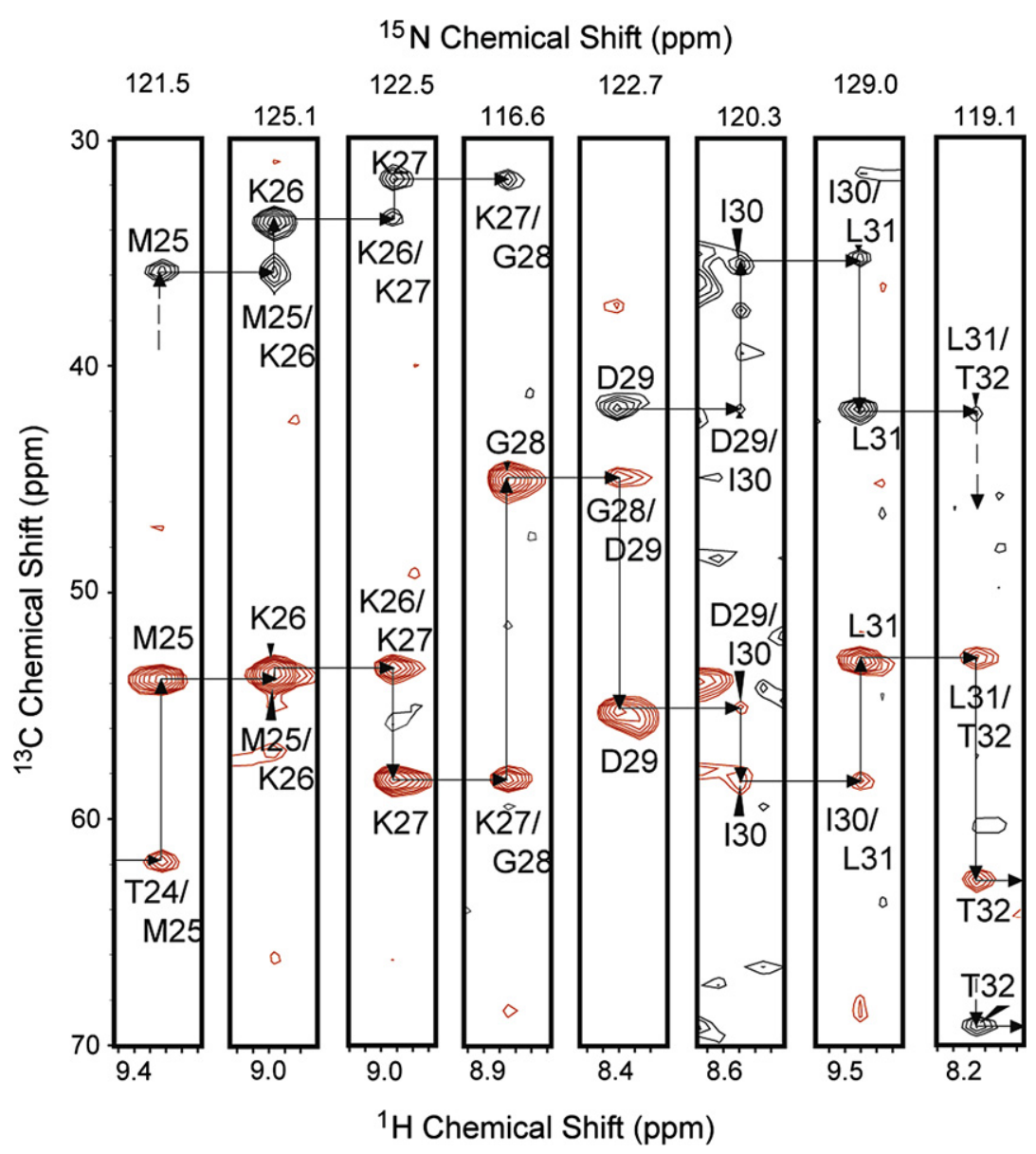

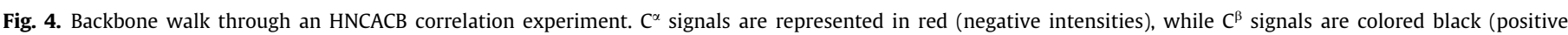

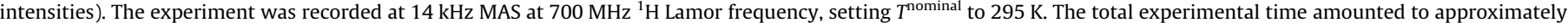
4.5 days.

overall signal-to-noise is reduced due to an additional relay step from $C^{\alpha}$ to $C^{\beta}$ implying a further $7 \mathrm{~ms}$ dephasing/rephasing period, during which transverse ${ }^{13} \mathrm{C}$ magnetization can decay. The overall duration of the sequence amounts to almost $70 \mathrm{~ms}$ prior to acquisition of the first ${ }^{13} \mathrm{C}$ increment. Compared to an HSQC reference experiment, signal to noise is decreased to around $3 \%$. Compared to the HNCA experiment, the longer sequence and the distribution of magnetization among multiple carbon resonances leads to some losses of resonances in the HNCACB. Twelve out of the 59 residues are lacking one correlation peak, mostly $C_{i-1}^{\beta} .5$ residues are missing two resonances, either both $\mathrm{C}^{\beta}$ correlations or both $\mathrm{C}^{\alpha} / \mathrm{C}^{\beta}$ correlations belonging to the amino acid $i-1$. In addition to the residues in the loop region, which could neither be observed nor assigned in the past, we observe a few weak signals in the HSQC that are, however, absent in the HNCACB like R21, S36, T37, and K43. Nevertheless, a sequential walk is possible for the greatest part of the backbone, making even the long HNCACB seem a generally applicable sequence for MAS solid-state NMR. The assignment that we obtain from scalar coupling based experiments compare well with the previously published chemical shifts of the SH3 domain of $\alpha$-spectrin $[43,44]$.

Better resolution in the ${ }^{13} \mathrm{C}$ dimension in the $\mathrm{HNCA}$ and HNCACB can in principle be obtained if ${ }^{2} \mathrm{H},{ }^{13} \mathrm{C}$ heteronuclear scalar decoupling were implemented [45]. This is, however, not possible in the current setup, as the employed probes are limited to triple resonance experiments.

\section{Conclusion}

In this work, we demonstrated that an exclusively scalar coupling based resonance assignment approach that relies on proton detection of extensively perdeuterated proteins is feasible in MAS solid-state NMR. In particular, we implemented HNCO, HNCA, HNCACB type experiments using pulse schemes adapted from solution-state NMR. Line widths for $\mathrm{H}^{\mathrm{N}}$ diluted perdeuterated samples are in the order of $20 \mathrm{~Hz}$, providing ${ }^{1} \mathrm{H} T_{2}$ relaxation times sufficiently long for scalar transfers. Although relaxation rates are still higher than rates obtained for small proteins in solution, 3D out-and-back experiments can be performed without complete loss of magnetization in the course of the pulse scheme. In order to compensate for the reduced signal intensity due to proton dilution, paramagnetic relaxation enhancement (PRE) was used to cut down recycle delays and thus reduce experimental time.

\section{Acknowledgments}

This work was supported by the Deutsche Forschungsgemeinschaft (DFG, Grants Re1435, SFB 449, SFB 740). R.L. is a Kekulé-scholar and acknowledges financial support of the Verband der Chemischen Industrie (VCI). We thank the Department of Structural Biology for support, in particular Peter Schmieder, Hartmut Oschkinat, and Barth van Rossum for stimulating discussions. 


\section{References}

[1] E.R. Andrew, A. Bradbury, R.G. Eades, NMR spectra recorded from a crystal rotated at high speed, Nature 182 (1958) 1659.

[2] A. Pines, M.G. Gibby, J.S. Waugh, Proton-enhanced NMR of dilute spins in solids, J. Chem. Phys. 59 (1973) 569-590.

[3] M. Hiller, L. Krabben, K.R. Vinothkumar, F. Castellani, B. Van Rossum, W. Kühlbrandt, H. Oschkinat, Solid-state magic-angle spinning NMR of outermembrane protein G from Escherichia coli, ChemBioChem 6 (2005) 1679-1684.

[4] A. Lange, K. Giller, S. Hornig, M.F. Martin-Eauclaire, O. Pongs, S. Becker, M. Baldus, Toxin-induced conformational changes in a potassium channel revealed by solid-state NMR, Nature 440 (2006) 959-962.

[5] M. Etzkorn, S. Martell, O.C. Andronesi, K. Seidel, M. Engelhard, M. Baldus, Secondary structure, dynamics, and topology of a seven-helix receptor in native membranes, studied by solid-state NMR spectroscopy, Angew. Chem. Int. Ed. 46 (2007) 459-462.

[6] V. Agarwal, U. Fink, S. Schuldiner, B. Reif, MAS solid-state NMR studies on the multidrug transporter EmrE, BBA Biomembranes 1768 (2007) 3036-3043.

[7] A.T. Petkova, Y. Ishii, J.J. Balbach, O.N. Antzutkin, R.D. Leapman, F. Delaglio, R. Tycko, A structural model for Alzheimer's $\beta$-amyloid fibrils based on experimental constraints from solid state NMR, Proc. Natl. Acad. Sci. USA 99 (2002) 16742-16747.

[8] C.P. Jaroniec, C.E. MacPhee, V.S. Bajaj, M.T. McMahon, C.M. Dobson, R.G. Griffin High-resolution molecular structure of a peptide in an amyloid fibril determined by magic angle spinning NMR spectroscopy, Proc. Natl. Acad. Sci. USA 101 (2004) 711-716.

[9] C. Ritter, M.-L. Maddelein, A.B. Siemer, T. Lührs, M. Ernst, B.H. Meier, S.J. Saupe, R. Riek, Correlation of structural elements and infectivity of the HET-s prion, Nature 435 (2005) 844-848.

[10] H. Heise, W. Hoyer, S. Becker, O.C. Andronesi, D. Riedel, M. Baldus, Molecularlevel secondary structure, polymorphism, and dynamics of full-length alphasynuclein fibrils studied by solid-state NMR, Proc. Natl. Acad. Sci. USA 102 (2005) 15871-15876.

[11] K.D. Kloepper, D.H. Zhou, Y. Li, K.A. Winter, J.M. George, C.M. Rienstra Temperature-dependent sensitivity enhancement of solid-state NMR spectra of alpha-synuclein fibrils, J. Biomol. NMR 39 (2007) 197-211.

[12] C. Wasmer, A. Lange, H. Van Melckebeke, A.B. Siemer, R. Riek, B.H. Meier Amyloid fibrils of the HET-s(218-289) prion form a beta solenoid with a triangular hydrophobic core, Science 319 (2008) 1523-1526.

[13] M. Baldus, A.T. Petkova, J. Herzfeld, R.G. Griffin, Cross polarization in the tilted frame: assignment and spectral simplification in heteronuclear spin systems, Mol. Phys. 95 (1998) 1197-1207.

[14] J. Pauli, M. Baldus, B.-J. Van Rossum, H. De Groot, H. Oschkinat, Backbone and side-chain ${ }^{13} \mathrm{C}$ and ${ }^{15} \mathrm{~N}$ signal assignments of the $\alpha$-spectrin $\mathrm{SH} 3$ domain by magic angle spinning solid-state NMR at 17.6 Tesla, ChemBioChem 2 (2001) 272-281.

[15] M. Baldus, Correlation experiments for assignment and structure elucidation of immobilized polypeptides under magic angle spinning, Prog. Nucl. Magn. Reson. Spectrosc. 41 (2002) 1-47.

[16] B. Reif, C.P. Jaroniec, C.M. Rienstra, M. Hohwy, R.G. Griffin, ${ }^{1} \mathrm{H}-{ }^{1} \mathrm{H}$ MAS correlation spectroscopy and distance measurements in a deuterated peptide J. Magn. Reson. 151 (2001) 320-327.

[17] B. Reif, R.G. Griffin, ${ }^{1} \mathrm{H}$ detected ${ }^{1} \mathrm{H},{ }^{15} \mathrm{~N}$ correlation spectroscopy in rotating solids, J. Magn. Reson. 160 (2003) 78-83.

[18] V. Chevelkov, B.J. van Rossum, F. Castellani, K. Rehbein, A. Diehl, M. Hohwy, S. Steuernagel, F. Engelke, H. Oschkinat, B. Reif, ${ }^{1} \mathrm{H}$ detection in MAS solid state NMR spectroscopy employing pulsed field gradients for residual solvent suppression, J. Am. Chem. Soc. 125 (2003) 7788-7789.

[19] E.K. Paulson, C.R. Morcombe, V. Gaponenko, B. Dancheck, R.A. Byrd, K.W. Zilm, High-sensitivity observation of dipolar exchange and NOEs between exchangeable protons in proteins by 3D solid-state NMR spectroscopy, J. Am. Chem. Soc. 125 (2003) 14222-14223.

[20] E.K. Paulson, C.R. Morcombe, V. Gaponenko, B. Dancheck, R.A. Byrd, K.W. Zilm, Sensitive high resolution inverse detection NMR spectroscopy of proteins in the solid state, J. Am. Chem. Soc. 125 (2003) 15831-15836.

[21] C.R. Morcombe, E.K. Paulson, V. Gaponenko, R.A. Byrd, K.W. Zilm, H-1-N-15 correlation spectroscopy of nanocrystalline proteins, J. Biomol. NMR 31 (2005) 217-230.

[22] M. Hologne, V. Chevelkov, B. Reif, Deuteration of peptides and proteins in MAS solid-state NMR, Prog. Nucl. Magn. Reson. Spectrosc. 48 (2006) 211-232

[23] D.H. Zhou, J.J. Shea, A.J. Nieuwkoop, W.T. Franks, B.J. Wylie, C. Mullen, D. Sandoz, C.M. Rienstra, Solid-state protein-structure determination with proton-detected triple-resonance 3D magic-angle-spinning NMR spectroscopy, Angew. Chem. Int. Ed. 46 (2007) 8380-8383.

[24] V. Chevelkov, K. Rehbein, A. Diehl, B. Reif, Ultra-high resolution in proton solidstate NMR at high levels of deuteration, Angew. Chem. Int. Ed. 45 (2006) 38783881.

[25] V. Chevelkov, K. Faelber, A. Diehl, U. Heinemann, H. Oschkinat, B. Reif, Detection of dynamic water molecules in a microcrystalline sample of the SH3 domain of $\alpha$-spectrin by MAS solid-state NMR, J. Biomol. NMR 31 (2005) 295310.

[26] B. Reif, B.J. van Rossum, F. Castellani, K. Rehbein, A. Diehl, H. Oschkinat, Determination of ${ }^{1} \mathrm{H}^{1} \mathrm{H}$ distances in a uniformly ${ }^{2} \mathrm{H},{ }^{15} \mathrm{~N}$ labeled $\mathrm{SH} 3$ domain by MAS solid state NMR spectroscopy, J. Am. Chem. Soc. 125 (2003) 1488-1489.

[27] V. Chevelkov, K. Faelber, A. Schrey, K. Rehbein, A. Diehl, B. Reif, Differential line broadening in MAS solid-state NMR due to dynamic interference, J. Am. Chem. Soc. 129 (2007) 10195-10200.

[28] V. Chevelkov, A. Diehl, B. Reif, Quantitative measurement of differential ${ }^{15} \mathrm{~N}-$ $\mathrm{H} \alpha / \beta \mathrm{T} 2$ relaxation times in a perdeuterated protein by MAS solid-state NMR spectroscopy, Magn. Res. Chem. 45 (2007) S156-S160.

[29] V. Chevelkov, A.V. Zhuravleva, Y. Xue, B. Reif, N.R. Skrynnikov, Combined analysis of ${ }^{15} \mathrm{~N}$ relaxation data from solid- and solution-state NMR spectroscopy, J. Am. Chem. Soc. 129 (2007) 12594-12595.

[30] V. Chevelkov, A. Diehl, B. Reif, Measurement of ${ }^{15} \mathrm{~N}-\mathrm{T}_{1}$ relaxation rates in a perdeuterated protein by MAS solid-state NMR spectroscopy, J. Chem. Phys. 128 (2008) 052316.

[31] V. Chevelkov, B. Reif, TROSY effects in MAS solid-state NMR, Concepts NMR 32A (2008) 143-156.

[32] M. Hologne, K. Faelber, A. Diehl, B. Reif, Characterization of dynamics of perdeuterated proteins by MAS solid-state NMR, J. Am. Chem. Soc. 127 (2005) $11208-11209$.

[33] B. Reif, Y. Xue, V. Agarwal, M.S. Pavlova, M. Hologne, A. Diehl, Y.E. Ryabov, N.R. Skrynnikov, Protein side-chain dynamics observed by solution- and solid-state NMR: comparative analysis of methyl ${ }^{2} \mathrm{H}$ relaxation data, J. Am. Chem. Soc. 128 (2006) 12354-12355.

[34] L.E. Kay, M. Ikura, R. Tschudin, A. Bax, Three-dimensional triple-resonance NMR spectroscopy of isotopically enriched proteins, J. Magn. Reson. 89 (1990) 496-514.

[35] S. Grzesiek, A. Bax, Improved 3D triple-resonance NMR techniques applied to a $31 \mathrm{kDa}$ protein, J. Magn. Reson. 189 (1992) 432-440.

[36] M. Wittekind, L.A. Mueller, HNCACB: a high-sensitivity 3D NMR experiment to correlate amide proton and nitrogen resonances with the alpha-carbon and beta-carbon resonances in proteins, J. Magn. Reson. B 101 (1993) 201-205.

[37] B. Elena, A. Lesage, S. Steuernagel, A. Böckmann, L. Emsley, Proton to carbon-13 INEPT in solid-state NMR spectroscopy, J. Am. Chem. Soc. 127 (2005) 1729617302.

[38] L.L. Chen, R.A. Olsen, D.W. Elliott, J.M. Boettcher, D.H.H. Zhou, C.M. Rienstra, L.J. Mueller, Constant-time through-bond C-13 correlation spectroscopy for assigning protein resonances with solid-state NMR spectroscopy, J. Am. Chem. Soc. 128 (2006) 9992-9993.

[39] L. Chen, J.M. Kaiser, T. Polenova, J. Yang, C.M. Rienstra, L.J. Mueller, Backbone assignments in solid-state proteins using $J$-based 3D heteronuclear correlation spectroscopy, J. Am. Chem. Soc. 129 (2007) 10650-10651.

[40] N.P. Wickramasinghe, M. Kotecha, A. Samoson, J. Past, Y. Ishii, Sensitivity enhancement in C-13 solid-state NMR of protein microcrystals by use of paramagnetic metal ions for optimizing H-1 T-1 relaxation, J. Magn. Reson. 184 (2007) 350-356.

[41] R. Linser, V. Chevelkov, A. Diehl, B. Reif, Sensitivity enhancement using paramagnetic relaxation in MAS solid state NMR of perdeuterated proteins, J. Magn. Reson. 189 (2007) 209-216.

[42] L. Emsley, G. Bodenhausen, Optimization of shaped selective pulses for NMR using a quaternion description of their overall propagators, J. Magn. Reson. 97 (1992) 135-148.

[43] F. Castellani, B.-J. van Rossum, A. Diehl, M. Schubert, K. Rehbein, H. Oschkinat, Structure of a protein determined by solid-state magic-angle spinning NMR, Nature 420 (2002) 98-102.

[44] B.-J. van Rossum, F. Castellani, J. Pauli, K. Rehbein, J. Hollander, H.J.M. De Groot, H. Oschkinat, Assignment of amide proton signals by combined evaluation of HN,NN and HNCA MAS-NMR correlation spectra, J. Biomol. NMR 25 (2003) 217-223.

[45] V. Agarwal, A. Diehl, N. Skrynnikov, B. Reif, High resolution ${ }^{1} \mathrm{H}$ detected ${ }^{1} \mathrm{H},{ }^{13} \mathrm{C}$ correlation spectra in MAS solid-state NMR using deuterated proteins with selective ${ }^{1} \mathrm{H},{ }^{2} \mathrm{H}$ isotopic labeling of methyl groups, J. Am. Chem. Soc. 128 (2006) 12620-12621. 